\title{
Effect of organic fertilizers used in sandy soil on the growth of tomatoes
}

\author{
Yongxia $\mathrm{Hou}^{1}$, Xiaojun $\mathrm{Hu}^{1^{*}}$, Wenting $\mathrm{Yan}^{2}$, Shuhong Zhang ${ }^{2}$, Libin $\mathrm{Niu}^{3}$ \\ ${ }^{1}$ Shenyang University, Key Laboratory of Regional Environment and Eco-Remediation, Ministry of Education, Shenyang, China; \\ houyongxia@126.com, ${ }^{*}$ Corresponding Author: hu-xj@mail.tsinghua.edu.cn \\ ${ }^{2}$ College of Horticulture, Shenyang Agricultural University, Shenyang, China; yanwenting2000@126.com, zhangsh024@163.com \\ ${ }^{3}$ The Affiliated Hospital of Liaoning University of Traditional Chinese Medicine, Shenyang, China; xiaojun7770@163.com
}

Received 2013

\begin{abstract}
In order to reveal the regulating capacity of organic fertilizers on sandy soil, pots experiments were carried out. The growth of tomatoes planted on sandy soil amended by organic fertilizers was measured. Organic fertilizers can be helpful to improve the plant height, stem diameter, the aerial parts fresh weight, root fresh weight, leaf photosynthetic rates and photosynthesis, and lay a good foundation for the growth of tomatoes. The effect of organic fertilizer is the most significant. Among all the treatments of adding $2.5 \%, 5 \%, 10 \%$ organic fertilizers, adding $10 \%$ organic fertilizers are the best. It can significantly enhance the growth and photosynthesis of tomatoes, and it is among the best of these three soil treatments for sandy soil.
\end{abstract}

Keywords: Sandy Soil; Organic Fertilizers; Photosynthetic Rate; Tomato

\section{INTRODUCTION}

Sandification is an environmental problem for the world. China is one of the countries suffered desertification seriously. In 2011, the State Forestry Administration (SFA) has announced the results of forth national monitoring of desertification and sandification. The results show that, by the end of 2009 , the area of national sandy lands, $18.03 \%$ of national lands, is $1,731,100 \mathrm{hm}^{2}$. In these areas, $310,000 \mathrm{hm}^{2}$ became sandy soil obviously. Some are still expanding. Sandy soil is a poor soil which has low contents of organic matters and nutrition. Owing to the loose texture and the gap between particles, the capacity of saving water and nutrients is poor. Not only was development soil productivity had constrained, but also the environmental deterioration and economic losses were getting worse and worse. Soil amendments have been reported to change sandy soil texture in order to increase water holding capacity [1]. Adding organic fertilizers in sandy soil, the growth of the plant growth was affected [2,3]. and in some cases neutralize soil acidity [3] and enhance soil catalase activity [4]. Horticultural production has an especially reliant relationship with soil. The overspread of cultivated lands is limited, but the amendable capacity is unlimited [5]. Soil amendments can not only change the characters of sandy soil, but enhance yield, quality [6] and stress resistance [7], promote the growth of horticultural plants. As the foundations of tomato growth, development and yield, photosynthesis is an important indicator in the fields of breeding, cultivation and environmental stress. The experiments reported here evaluated the use of organic fertilizers to improve the plant height, stem diameter, the aerial parts fresh weight, root fresh weight, leaf photosynthetic rates and photosynthesis by two kinds of sandy soil, for revealing the regulating capacity of organic fertilizers on sandy soil.

\section{MATERIALS AND METHODS}

\subsection{Materials and Experimental Design}

Experiments were conducted at the greenhouse of Shenyang University. The soil is sandy soil. Strong sandy soil was taken from Dong Liujiazi located in $42^{\circ}$ $20^{\prime} 43 \mathrm{~N}, 122^{\circ} 43^{\prime} 19 \mathrm{E}$. Weak sandy soil were taken from Xiu Shuihe in Faku located in $42^{\circ} 21^{\prime} 26 \mathrm{~N}, 123^{\circ} 00^{\prime} 21 \mathrm{E}$. Organic fertilizer was purchased from flower market. The variety of tomato for experiment is Fuyou Dafen.

These were pots experiments. These soil amendments of organic fertilizers were respectively added to two kinds of sandy soil at the mass ratios of $2.5 \%, 5 \%$ and $10 \%$. There were 20 treatments. Each one had 5 repetitions. The experimental treatments are showed as follows (Table 1).

Tomatoes were seeded on February 22, 2012 and planted in pots on March 28. Except the amounts of soil amendments and sandy soil, each one was used by one routine management. 
Table 1. Treatments.

\begin{tabular}{ccccc}
\hline Treatments & $\begin{array}{c}\text { Organic fertilizer } \\
\left(\mathrm{g} \cdot \mathrm{kg}^{-1}\right)\end{array}$ & $\begin{array}{c}\text { Strong sandy } \\
\text { soil }\left(\mathrm{g} \cdot \mathrm{kg}^{-1}\right)\end{array}$ & $\begin{array}{c}\text { Weak sandy } \\
\text { soil }\left(\mathrm{g} \cdot \mathrm{kg}^{-1}\right)\end{array}$ & $\begin{array}{c}\text { Mass rotio } \\
(\%)\end{array}$ \\
\hline CK(A) & 0 & 1000 & 0 & 0 \\
$\mathrm{~A} 1$ & 25 & 975 & 0 & 2.5 \\
$\mathrm{~A} 2$ & 50 & 950 & 0 & 5 \\
$\mathrm{~A} 3$ & 100 & 900 & 0 & 10 \\
$\mathrm{CK}(\mathrm{B})$ & 0 & 1000 & 0 & 0 \\
B1 & 25 & 0 & 975 & 2.5 \\
$\mathrm{~B} 2$ & 50 & 0 & 950 & 5 \\
B3 & 100 & 0 & 900 & 10 \\
\hline
\end{tabular}

\subsection{Experimental Methods}

The parameters of plant height, stem diameter, the aerial parts fresh weight, root fresh weight were investigated by conventional techniques. By using Lc Pro+ photosynthesis system, the light responses of photosynthesis in leaves of 60 days after planted tomatoes were studied under 2 different soil water conditions: drought (Relative Soil Water Content (RSWC) is $60 \%$ ) and saturated-water (RSWC is $100 \%$ ). The measure time was during 10:00 - 12:00 on sunny days. The third healthy functional leaves were chosen from the top as samples, every treatment took 5 samples. The average values were as the final measured results. Artificial light source were used to control Photosynthetic Photon Flux Density (PPFD). The PPFD were $600,800,1000,1200,1400$, and $1600 \mu \mathrm{mol} \cdot\left(\mathrm{m}^{2} \cdot \mathrm{s}\right)^{-1}$. Determined time was $60 \mathrm{~s}$ under each PPFD.

\section{RESULTS AND DISCUSSION}

\subsection{Effect of Adding Organic Fertilizers on the Growth of Tomato}

Adding $2.5 \%, 5 \%, 10 \%$ organic fertilizers in strong sandy soil obviously improved the parameters of the plant height, stem diameter, the aerial parts fresh weight, root fresh weight of tomato leaves (Table 2). And it had the same trend in weak sandy soil. The parameters of the plant height, stem diameter, the aerial parts fresh weight, root fresh weight improve with the increasing of organic fertilizers.

\subsection{Effect of Adding 2.5\% Organic Fertilizers on Photosynthetic Rate of Tomato}

Adding $2.5 \%$ organic fertilizers in strong sandy soil obviously improved photosynthetic rates of tomato leaves
(Figure 1). Photosynthetic rates of plants treated by organic fertilizers increased rapidly with the raising of PPFD. With raising trends of the rates got slowly later. The results showed that when the RSWC was $60 \%$, the photosynthetic rate of adding organic fertifizer increased apparently to the max value of $7.13 \mu \mathrm{mol} \cdot\left(\mathrm{m}^{2} \cdot \mathrm{s}\right)^{-1}$ under $1600 \mu \mathrm{mol} \cdot\left(\mathrm{m}^{2} \cdot \mathrm{s}\right)^{-1}$ PPFD. The increased tendency of tomato photosynthetic rates of every treatments under $100 \%$ RSWC was the same as that in drought condition (RSWC is $60 \%$ ). The max was $8.74 \mu \mathrm{mol} \cdot\left(\mathrm{m}^{2} \cdot \mathrm{s}\right)^{-1}$ from organic fertifizer used treatment. By comparing the treatment of A1 and B1, 2.5\% soil amendments made a better influence in weak sandy soil than that in strong sandy soil.

\subsection{Effect of Adding 2.5\% Organic Fertilizers on Photosynthetic Rate of Tomato}

According to Figure 2, after adding 5\% organic fertilizers in strong sandy soil, the photosynthetic rate of tomatoes got an obvious enhancement. With the PPFD

Table 2. The effect of organic fertilizers on the growth of tomato in flowering stage.

\begin{tabular}{ccccc}
\hline Treatments & $\begin{array}{c}\text { plant height } \\
(\mathrm{mm})\end{array}$ & $\begin{array}{c}\text { stem diameter } \\
(\mathrm{mm})\end{array}$ & $\begin{array}{c}\text { the aerial parts } \\
\text { fresh weight }(\mathrm{g})\end{array}$ & $\begin{array}{c}\text { root fresh } \\
\text { weight }(\mathrm{g})\end{array}$ \\
\hline $\mathrm{CK}(\mathrm{A})$ & 201.08 & 2.84 & 3.15 & 0.51 \\
$\mathrm{~A} 1$ & 207.45 & 2.9 & 3.24 & 0.58 \\
$\mathrm{~A} 2$ & 257.3 & 3.0 & 3.35 & 0.75 \\
$\mathrm{~A} 3$ & 286.54 & 3.1 & 4.11 & 0.85 \\
$\mathrm{CK}(\mathrm{B})$ & 204.92 & 2.85 & 3.54 & 0.65 \\
B1 & 214.38 & 2.96 & 4.03 & 0.69 \\
B2 & 223.19 & 3.14 & 5.09 & 0.71 \\
B3 & 294.9 & 3.38 & 5.53 & 0.82 \\
\hline
\end{tabular}

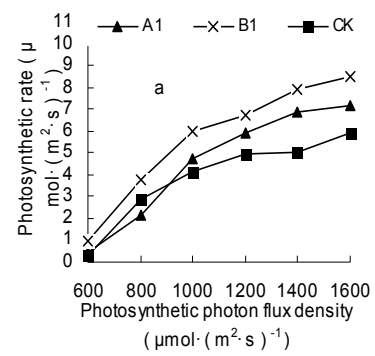

(a)

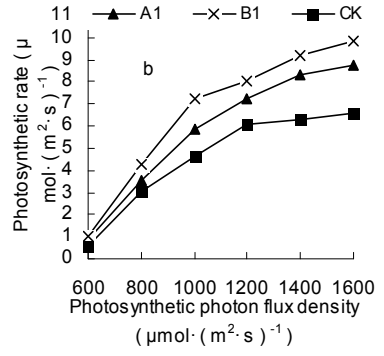

(b)
Figure 1. Photosynthetic rate-light response curves of tomato under adding $2.5 \%$ soil amendments in strong sandy soil and weak sandy soil: (a) Drought condition (RSWC is 60\%); (b) Saturated-water con-dition ( RSWC is $100 \%$ ). 
raising, the photosynthetic rates of the treatments increased rapidly. It was an evident improvement of tomato photosynthetic rate on sandy soil amended by organic fertilizers under $60 \%$ RSWC, while the PPFD was 1600 $\mu \mathrm{mol} \cdot\left(\mathrm{m}^{2} \cdot \mathrm{s}\right)^{-1}$, to the $\max 7.69 \mu \mathrm{mol} \cdot\left(\mathrm{m}^{2} \cdot \mathrm{s}\right)^{-1}$. After rewatering, the tomato photosynthetic rates tendency of every treatments was simillar to that in drought condition (RSWC is $60 \%$ ). The max was $9.62 \mu \mathrm{mol} \cdot\left(\mathrm{m}^{2} \cdot \mathrm{s}\right)^{-1}$ from organic fertilizers used treatment. After applying 5\% soil amendments on weak sandy soil, it showed that the tomato photosynthetic rate of each treatment in drought condition was higher than that in saturated-water condition by analyzing the effects of different relative soil water contents. The amending effect of adding 5\% amendments on weak sandy soil was better than that on the strong one.

\subsection{Effect of Adding $10 \%$ Soil Amendments on Photosynthetic Rate of Tomato}

The tomato photosynthetic rate under $10 \%$ organic fertilizers used was increasing with photosynthetic photon flux density (Figure 3). All got the top value when the PPFD was $1600 \mu \mathrm{mol} \cdot\left(\mathrm{m}^{2} \cdot \mathrm{s}\right)^{-1}$. The effect of the treatment of adding $10 \%$ organic fertilizers was better than that of ck in drought condition, the max $7.41 \mu \mathrm{mol} \cdot\left(\mathrm{m}^{2} \cdot \mathrm{s}\right)^{-1}$. When RSWC was $100 \%$, the max values of organic fertilizers was $9.21 \mu \mathrm{mol} \cdot\left(\mathrm{m}^{2} \cdot \mathrm{s}\right)^{-1} .10 \%$ organic fertilizers

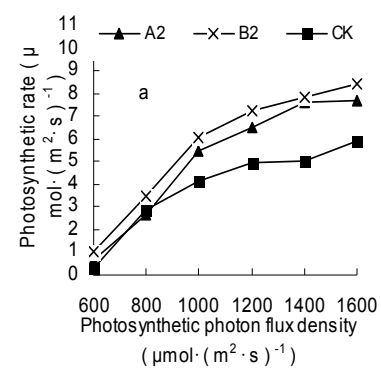

(a)

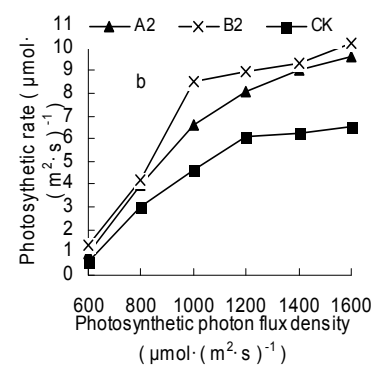

(b)
Figure 2. Photosynthetic rate-light response curves of tomato under adding 5\% soil amendments in strong sandy soil and weak sandy soil.

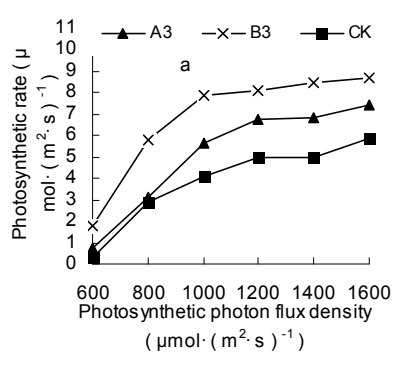

(a)

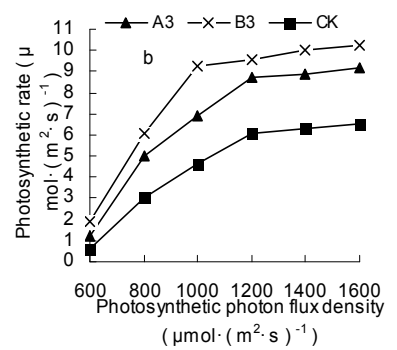

(b)
Figure 3. Photosynthetic rate-light response curves of tomato under adding 10\% soil amendments in strong sandy soil and weak sandy soil: (a) Drought condition (RSWC is 60\%); (b) Saturated-water condition (RSWC is $100 \%$ ). made a better influence in weak sandy soil than that in strong sandy soil. The effects of all the treatments on enhancing tomato photosynthetic rate were better than that of control sample.

\section{Conclusions}

This study showed that after adding two kinds of sandy soil by adding $2.5 \%, 5 \%$ and $10 \%$ organic fertilizers under different relative soil water contents, the growth of the plant height, stem diameter, the aerial parts fresh weight, root fresh weight and the photosynthetic rates of tomato affected by organic fertilizer were all enhanced. the effect of using organic fertilizers was obvious. It showed that organic fertilizers could enhance crop physiological activity effectively, improve photosynthsis, and promote the growth of tomato. In addition, they could also enhance the accumulation of photosynthetic production, and establish the foundation of yield and quality. It is probably that organic fertilizers have multi-nutrients for the crop growth, and the ability of improving soil texture and nutritional status. Under the same organic fertilizers used, the effect in saturated-water condition was better than that in drought condition. It showed that the photosynthsis of tomato rebounded after rewatering. The reason is probable that organic fertilizers could enhance the soil water-nutrition holding capacity, and amend the weakness of sandy soil. By comparing the effects on different sandy soil, the photosynthetic rates on weak soil all higher than that on strong soil. The general analysis showed that adding $10 \%$ organic fertilizers was the best way to improve photosynthetic rate and growth of tomato.

\section{ACKNOWLEDGEMENTS}

This work has been supported by National Natural Science Foundation of China (21277093), Liaoning BaiQianWan Talents Program (2010921004), Natural Science Foundation of Liaoning Province of China (201102156) and Program for Liaoning Excellent Talents in University (LR2011034) and the National Science and Technology Supporting Project (2011BAJ06B02).

\section{REFERENCES}

[1] Busscher, W.J., Novak, J.M. and Caesar-tonthat, T.C. (2007) Organic matter and polyacrylamide amendment of Norfolk loamy sand. Soil \& Tillage Research, 171-178.

[2] Zhang, B.B., Guo, J.B. and Jiang, K.Y. (2011) Effects of Arkadolith soil modifier on sand soil's properties and growth of Astragalus Mongolicum. Bulletin of Soil and Water Conservation, 190-194.

[3] Cui, J.Y., Li, Y.L. and Su, Y.Z. (2002) Experiment of using fermented waste residue from alcohol production to improve sandy soil. Journal of Desert Research, 368-371.

[4] Cui, L.L., Li J.J. and Zou, G.Y. (2004) Effect of bentonite 
on sandy soil fertility. Acta Agriculture Boreali- Sinica, 76-80.

[5] Zhang, Z.X. ( 2005) Theory and practice of half dry identify water saving agriculture on northeastern China. China Agriculture Press.

[6] Chen, F.S., Zeng D.H. and Chen, G.S. (2003) Effects of peat and weathered coal on physiological characteristics and growth of Chinese cabbage on aeolian sandy land. Journal of Soil and Water Conservation, 152-155.

[7] Giri, B., Kapoor, R. and Mukerjik, G. (2003) Influence of arbuscular mycorrhizal fungi and salinity on growth, biomass and mineral nutrition of Acacia auriculiformis. Biology and Fertility of Soils, 38, 170-175. doi: 10.1007/s00374-003-0636-z 